\title{
O DIREITO PENAL COMO ULTIMA RATIO
}

Graziella de Holanda e Silva; Cyntia Cardoso Santos; Eduardo Buzetti Eustachio Bezerro

Universidade do Oeste Paulista - UNOESTE, curso de Direito, Presidente Prudente, SP. E-mail: grazihollanda@gmail.com

\section{RESUMO}

Ao acessarmos qualquer fonte de noticia, grande parte dos noticiários são assuntos decorrentes do Direito Penal, homicídio, roubo, furto entre outros. Longínquo o tempo em que se predominava na sociedade a vingança privada, motivada por uma ausência estatal que causava em cada individuo uma maior busca por seus interesses particulares. Ao transcorrer do tempo, o Estado vai se amoldando em sua nova roupagem, criando força e presença em meio à sociedade. Mas a função do direito penal não mora na punição de qualquer natureza, haja vista uma extensa variedade de Direito em nosso ordenamento jurídico, devendo o Direito Penal ser aplicado como o ultimo remédio, a "ultima ratio" baseado no Princípio da dignidade da pessoa humana, não pode o direito penal servir como única forma de controle social. Pois tal utilização exarcebada do mesmo, acaba por minar a sua eficiência e diminuir também, a sua capacidade de inibir o cometimento de mais crimes.

Palavras-Chave: Direito Penal, Ultima ratio, Princípio da Dignidade da Pessoa Humana, Controle Social.

\section{THE CRIMINAL LAW AS LAST RATIO}

\begin{abstract}
When accessing any source of news, most of the news are issues arising from criminal law, murder, robbery, robbery among others. Long ago the time in which prevailed in the society the private revenge, motivated by a state absence that caused in each individual a greater search for its particular interests. Over time, the state is molding itself in its new garb, creating strength and presence in the midst of society. But the function of criminal law does not dwell on punishment of any nature, given the wide variety of law in our legal system, and Criminal Law should be applied as the ultimate remedy, the ultima ratio based on the Principle of the dignity of the human person, Criminal law can not serve as the only form of social control. For such exacerbated use of it, ends up undermining its efficiency and diminishing also, its ability to inhibit the commission of more crimes.
\end{abstract}

Keywords: Criminal Law, Ultima ratio, Principle of Dignity the Human Person, Social Control.

\section{INTRODUÇÃO}

Proporcionalmente ao crescimento da população, crescem também os conflitos, se fazendo necessário um maior cuidado por parte do Estado em relação a forma como tais litígios são resolvidos. Não existindo mais espaço para a vingança privada, nasce assim o Direito Penal, que visa garantir os direitos do apenado, ou seja, protege-lo dos excessos outrora cometidos.

Tal ramo do Direito nasce com o propósito de deixar de lado as vinganças privadas, de forma que somente o que fosse mais gravoso pudesse custar ao cidadão a sua liberdade, limitando também esse poder punitivo ao Estado. Tal finalidade é conhecida como 'ultima ratio', 
ou seja, somente em último caso seria aplicado o Direito Penal, visando garantir a aplicação dos Princípios da Dignidade da Pessoa Humana e o da Necessidade.

O estudo tem por objetivo refletir sobre a utilização do Direito Penal como forma de assegurar conflito, questionando se este está realmente sendo utilizado apenas em casos em que nenhum outro direito consiga alcançar, neste contexto há uma grande necessidade de uma mudança do Código Penal, onde deva ser tirado dos cuidados do Direito Penal, assuntos que podem ser cuidados por outros ramos do Direito.

A sociedade, de maneira geral, carece de soluções práticas para vários problemas sociais existentes. Trata-se de uma reflexão embasada em bibliografia diversa, fundamentada em leituras, fichamentos de livros, artigos eletrônicos, periódicos, leis, decretos, jurisprudências, entre outros.

O estudo em apreço é de extrema importância, haja vista que aguçará a discussão de acadêmicos quanto ao tema, propiciando novos entendimentos e novos questionamentos sobre estes, para que a partir daí, todos possam exercer sua opinião critica a respeito do assunto apresentado, acarretando novos apontamentos no âmbito de pesquisas, buscando colocações sensatas sobre tal.

\section{METODOLOGIA}

O presente trabalho teve seu desenvolvimento por meio de diversas pesquisas bibliográficas, leituras, artigos eletrônicos, observação de tal tema em seu desenvolvimento prático, frente a realidade social. Discussão principalmente por meio do emprego do método hipotético-dedutivo.

Desenvolvido com o apoio do orientador, de forma a apresentar mais clareza e mais foco ao estudo, em observância a realidade social e aquela apresentada em nossa Legislação. Buscarse-á uma discussão partindo do raciocínio lógico geral para o particular. Todos os dados coletados serão discutidos, confrontados e argumentados dialeticamente.

\section{DISCUSSÃO}

Ao observarmos a evolução histórica dos conflitos sociais, notamos que os interesses individuais eram alcançados sem nenhuma intervenção estatal, até mesmo por haver, nesses momentos mais arcaicos a figura do Estado, dessa forma conseguiria alcançar sua pretensão aquele que possuía mais força ou então que detinha mais poder.

Cita Estefam (2013, p. 35), "Registram os historiadores que nas tribos, desde a antiguidade, já se notava, incutida no espírito humano, a ideia de castigo por atos lesivos a terceiros, muito embora, em tempos remotos, era a vingança privada que imperava.".

Nesta época, a sociedade era estruturada por um ambiente familiar, as penas eram impostas a aqueles que perturbavam a paz e da vida em sociedade quando estes eram membros da mesma tribo, eram punidos pela morte ou fugiam se assim conseguisse. Para estranhos a pena era de conotação vingativa, sendo estes considerados "estrangeiros" (ESTEFAM, 2013, p. 35).

Ante o exposto, após um avanço gradativamente lento, surgiu o Estado como responsável de zelar pela segurança e pelos interesses sociais, a partir deste momento é que surgem os vários direitos e deveres individuais.

Com Direito Penal, visto como um direito positivo foi instituindo como "ultima ratio" ou intervenção mínima, devendo ser aplicado no campo onde nenhum outro direito existente consiga alcançar. O Direito penal é o segmento do ordenamento jurídico que seleciona as condutas mais graves, haja vista, estas causarem insegurança jurídica e trazer maior risco à sociedade. (CAPEZ, 2011, p. 19).

Para que possa existir um convívio harmônico entre os integrantes da sociedade, necessário se faz que haja regras regulamentando as condutas aceitas e as condutas reprováveis, 
essas regras denominam-se Direito Positivo, que devem ser obedecidas por todos. (MIRABETE, 1990, p. 21).

Ao observarmos o Código Penal em sua integridade, encontramos artigos que não necessariamente ali deveriam estar, haja vista que o problema ali discutido poderia ser solucionado por outros ramos do direito. Desta forma, ao passo que tal código é analisado detalhadamente, nota-se que há um excessivo número de artigos regulando situações que não seriam da alçado do Direito Penal.

Conforme o mencionado acima, surge a figura do Direito Penal simbólico, onde devido a sua grande rigorosidade, acabando por ser ineficaz na pratica ou deixando cair no vazio de sua aplicação, onde o Legislador traz a sociedade uma falsa ideia de segurança, onde o cidadão acredita ter realmente um direito tutelado, mas ao impulsiona-lo não possui nenhuma resposta vinda do Direito Penal (TORRES, 2001, s/p).

Nesta mesma linha, leciona Rogério Greco:

A finalidade do Direito Penal é a proteção dos bens jurídicos mais importantes e necessários para a própria sobrevivência da sociedade. Para efetivar essa proteção utiliza-se da cominação, aplicação e execução da pena. A pena não é a finalidade do direito penal. É apenas um instrumento de coerção de que se vale para a proteção desses bens, valores e interesses mais significativos da sociedade.

Seja com penas de prisão, "penas alternativas" ou "consensuadas", o Direito Penal não se contrai nem fragmenta. O que se verifica constantemente é uma expansão incontrolada da seara penal, uma verdadeira criminalização generalizada dos mais diversos conflitos e problemas sociais e individuais. (CABETTI, 2012, s/p).

Em razão de tais fatos apresentados, podemos notar uma grande expansão da Lei Penal, buscando intermediar todas as relações sociais, perdendo o seu conceito precípuo de "ultima ratio", motivo pelo qual, perde sua eficácia e sua real aplicabilidade.

Neste sentido salienta Pierpaolo Cruz Bottini (2013, s/p):

Se o direito penal é a ultima ratio do controle social, se é tratado como o instrumento que age apenas diante de ineficácia de outros mecanismos de inibição de condutas, como explicar a legitimidade da pena para uma ação ou omissão considerada lícita na seara cível ou administrativa?

O Direito Penal como "ultima ratio" baseia-se no princípio da Dignidade da Pessoa Humana, que não é tratada por todos os autores como um princípio, haja vista a sua ausência em nosso ordenamento jurídico, tratando esta apenas como um atributo possuidor de todo ser humano. A dignidade da Pessoa Humana é vista como valor constitucional supremo, o núcleo axiológico da Constituição. (SOUZA JÚNIOR, s/p).

Conforme o princípio anteriormente mencionado, delimita VECCHIETTI (2010, s/p):

Para garantir o bem da sociedade, é preciso agir dentro de certos parâmetros de razoabilidade, necessidade e principalmente destacar a importância do princípio da dignidade da pessoa humana. Por essa razão, o postulado máximo de que "os fins justificam os meios" não deve ser utilizado na aplicação das regras, quando se estiver tutelando interesses no Estado Democrático de Direito.

Ainda esclarece Vicchietti (2010, s/p) que, antes da utilização do Direito Penal, é necessário que seja adotada outras medidas para que as regras sejam cumpridas espontaneamente, a partir 
da omissão e tais cumprimentos espontâneos, deverá ser aplicada sanções, podendo estas serem penais ou não.

Por fim, o objetivo principal de tal estudo, é esclarecer o papel do Direito Penal, desde sua origem, papel esse, que ao passar dos anos tem se transformado de maneira a torna-lo ineficiente, o chamado Direito Penal simbólico. Procurando assim, propor uma discussão em relação ao que se pode fazer para que o Direito Penal retorne à sua finalidade primária, e mais do que isso, seja uma fonte eficaz de controle social.

\section{CONCLUSÃO}

Conforme estudado, a principal função do Direito Penal dentro do ordenamento jurídico brasileiro é tutelar o convívio e os interesses sociais, conforme o emana do Princípio da Dignidade da Pessoa Humana. A partir do momento em que a Função do Direito Penal se torna nebulosa, frente a tantos assuntos confiados a sua vigia, assuntos estes que poderiam ser delegados a outros ramos do Direito, há um crescente enfraquecimento da lei penal quanto a sua aplicação.

Não há que se falar que a lei Penal é totalmente ineficaz, haja vista que possuímos a Lei Especial Penal, que traz em seu conteúdo, casos em que realmente o Direito Pernal é considerado a "ultima ratio", logo, não carece de nosso Legislador uma mudança radical em nossa Legislação Penal, necessitando apenas de uma reforma frente a assuntos peculiares que poderiam ser confiados a outros ramos do direito, deixando aos cuidados do Direito Penal, casos que realmente este se faz necessário.

É necessário que a sociedade entenda de forma ética e humanitária qual a verdadeira função do Direito Penal, não apresentando a esta diversos cenários onde a aplicação de outro ramo do Direito seria mais eficaz e produtiva para a própria sociedade.

\section{REFERÊNCIAS}

BOTTINI, Pierpaolo. Independência das esferas administrativa e penal é mito. Disponível em: <http://www.conjur.com.br/2013-mai-21/direito-defesa-independencia-ambitos-administrativopenal-mito>. Acesso em: 07 ago. 2017.

CABETTE, Eduardo Luiz Santos. Teoria pura e mínima do direito penal. Disponível em: <https://eduardocabette.jusbrasil.com.br/artigos/121937325/teoria-pura-e-minima-do-direitopenal>. Acesso em: 09 ago. 2017.

CAPEZ, Fernando. Curso de direito Penal. 15 Ed. São Paulo: Saraiva, 2011. Disponível em <http://unesav.com.br/ckfinder/userfiles/files/Curso_de_Direito_Penal_1_-

_Parte_Geral_15_edicao\%5B1\%5D.pdf>. Acesso em 8 ago. 2017.

ESTEFAM, André. Direito Penal. 3ạ Ed. São Paulo: Saraiva, 2013.

GRECO, Rogério. Curso de Direito Penal- Parte Geral. Disponível em: <https://www.passeidireto.com/arquivo/6189307/direito_penal_parte_geral_rogerio_greco>. Acesso em: 09 ago. 2017.

MIRABETE, Júlio Fabrini. Manual de Direito Penal. 5a Ed. São Paulo: Editora Atlas S. A., 1990. 
SOUZA JUNIOR, Luiz Lopes. A dignidade da pessoa humana e os direitos fundamentais. Disponível em: $\quad<$ http://www.coladaweb.com/direito/a-dignidade-da-pessoa-humana-e-os-direitosfundamentais>. Acesso em: 09 ago. 2017.

TORRES, Douglas Dias. 0 Direito Penal na atualidade. Disponível em: <http://www.direitonet.com.br/artigos/exibir/333/O-Direito-Penal-na-atualidade>. Acesso em: 08 ago. 2017.

VECCHIETTI, Gustavo Nascimento Fiuza. "Ultima ratio" do Direito Penal. Disponível em: <https://jus.com.br/artigos/18001/ultima-ratio-do-direito-penal>. Acesso em 08 ago. 2017. 